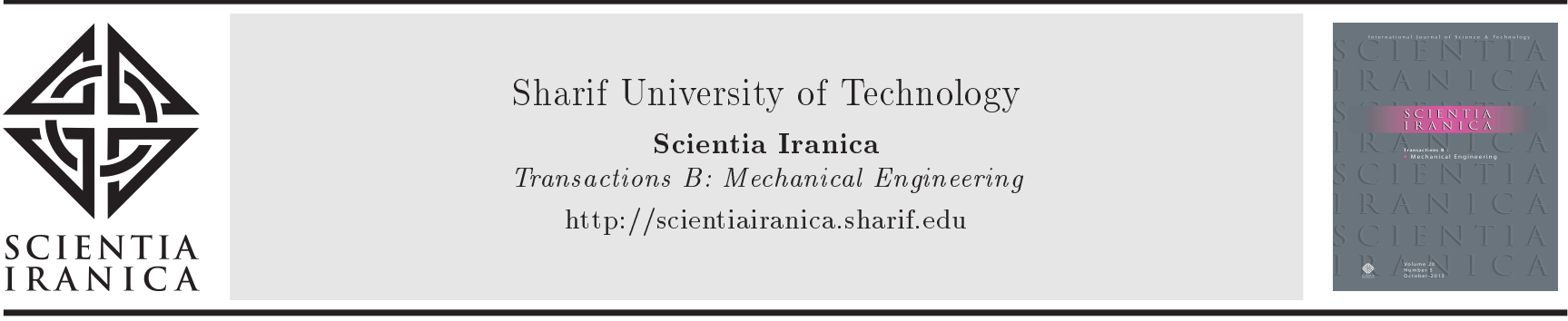

\title{
Tribological behavior of the refined, bleached, and deodorized palm kernel as an alternative lubricant
}

\author{
A.N. Farhanah* and S. Syahrullail \\ Faculty of Mechanical Engineering, Universiti Teknologi Malaysia, 81310 UTM Johor Bahru, Johor, Malaysia.
}

Received 11 November 2015; received in revised form 14 February 2017; accepted 30 May 2017

\section{KEYWORDS}

ZDDP;

Pin-on-disk;

RBD palm kernel;

Friction;

Wear;

Surface roughness.

\begin{abstract}
The effects of zinc dialkyl dithiophosphate (ZDDP) concentration on tribological behavior of the Refined, Bleached, and Deodorized (RBD) palm kernel were analyzed using a pin-on-disk tribotester. RBD palm kernel was selected as a base lubricant due to its availability, low price, renewability, and being environmentally friendly. Commercial mineral oil (SAE 40) was used for comparison. The tests were performed at $2.5 \mathrm{~m} / \mathrm{s}$ sliding speed under $9.8 \mathrm{~N}$ applied load for 60 minutes at $25^{\circ} \mathrm{C}$ temperature $\left( \pm 2^{\circ} \mathrm{C}\right)$. Worn surface of the pin was measured by the optical microscope to understand the wear mechanism involved. Compared with SAE 40, experimental results show that the addition of $5 \mathrm{wt} \%$ of ZDDP reduced the coefficient of friction to $21 \%$. However, the anti-wear property was still lower, approximately at $23 \%$. Besides, the tribological behavior of RBD palm kernel was improved with ZDDP additive concentration above $1 \mathrm{wt} \%$ where the best performance was at $5 \mathrm{wt} \%$. At this concentration level, ZDDP additive was able to protect the surface against wear and oxidation and, at the same time, reduce coefficient of friction, wear rate, and surface roughness values.
\end{abstract}

(C) 2018 Sharif University of Technology. All rights reserved.

\section{Introduction}

Lubricants are used widely in many industries to lubricate contact surfaces in machineries in order to minimize friction and wear, improve efficiency, and extend their life-time [1]. Mineral and synthetic oil-based lubricants are extensively used in various applications such as industrial gears and hydraulic systems, automotive engines, transmission and hydraulic systems, metalworking applications, and many others [2]. However, those lubricants are not readily biodegradable and are highly toxic, since they contain many types of additives where, generally, mineral oil consists of about $70 \%$ to $99 \%$ base oil and $1 \%$ to $30 \%$

*. Corresponding author. Tel.: +6019 2874079 E-mail addresses: nurulfarhanahazman@gmail.com (A.N. Farhanah); syahruls@mail.fkm.utm.my (S. Syahrullail)

doi: $10.24200 /$ sci. 2017.4339 additives [3]. Environmental issues and depletion of world petroleum reserves have buzzed the alarmed to find alternative lubricants to replace these mineral oilbased lubricants.

For the past few decades, vegetable oils have received much attention to use as a lubricant base stock. It is preferred due to its advantages such as being nature friendly, renewability, non-toxicity, biodegradability, high lubricity and viscosity level, high viscosity index, high flash point, low volatility, and high shear stability [4-6]. There have been relatively few recent studies on palm oil to be used as additive mineral oilbased lubricants, biodiesel production, and lubricant base stock [7-10]. Palm oil is one of the economical vegetable oils in Malaysia, and Malaysia is the one of the world's largest producer of palm oil [11]. Palm oil is currently used in food and biodiesel production. Nevertheless, very few studies have been conducted on palm oil as a lubricant base stock. Optimizing the usage of palm oil will promote its potential as lubricants 
in order to fulfill the worldwide demands in the near future and, at the same time, contribute to Malaysia's economic growth.

Vegetable oils are well known as good lubricants as compared to mineral oil; however, additional additives are still required to improve lubricity and control friction and wear. There are several types of additives that can be used depending on the specific demands and additional performance on the characteristics needed for the lubricants. These include detergents and dispersants, anti-wear agents, antifoams, emulsifiers, Extreme Pressure (EP), pour point improvers, Viscosity Index (VI) improvers, corrosion inhibitors, antioxidants, and friction modifiers [12]. Vegetable oils have high solubilizing power for polar contaminants and additive molecule [13]. Zinc dialkyl dithiophosphate (ZDDP) are widely used as an additive in formulating lubrication oils due to its multifunctional as anti-wear, Extreme Pressure (EP), and antioxidants additives [14].

There are several findings on the performance of vegetable oils as a base lubricant formulated with ZDDP additive. Mahipal et al. [15] revealed that ZDDP functions effectively in Karanja oil to reduce friction and wear. An experiment was conducted using a four-ball tester as per ASTM D4172 B. It was found that Karanja oil is a better lubricant than commercial mineral oil (SAE 20W 40) at a concentration of $2.0 \mathrm{wt} \%$ of the ZDDP. Another research done by Jayadas et al. [16] proved that ZDDP functions well as an antiwear and Extreme Pressure (EP) agent in coconut oil. Tribological properties of coconut oil were tested using a four-ball tester as per ASTM D2783. It was also found that there is a positive improvement to tribological properties of coconut oil when added with $2 \mathrm{wt} \%$ of the AW/EP additive. Moreover, Asadauskas et al. [17] reported that ZDDP performs more effectively as EP additives in soybean oil, compared with mineral oil.

Previous researches conducted an experiment on palm oil to use as an additive in mineral oil-based lubricants, as biodiesel production, and as lubricant base stock [7-10]; however, there are limited references to the Refined, Bleached and Deodorized (RBD) palm kernel as a base lubricant formulated with ZDDP additive. In this study, tribological properties of RBD palm kernel with various concentrations of ZDDP additive were evaluated using a modified pin-on-disk tribotester. Commercial mineral oil (SAE 40) was used for comparison. RBD palm kernel was selected as the base lubricant since palm oil is widely produced in Malaysia and low in price. It was also selected due to its renewable properties and environmentally friendly characteristics. ZDDP additive was selected to determine their effectiveness in reducing friction and wear of the base lubricant.

\section{Experimental details}

\subsection{Pin-on-disk tribotester}

Tribological properties of the tested lubricants were evaluated using a pin-on-disk tribotester (see Figure 1). Normal force was applied using dead weight that has been suspended at one end of the lever. The friction force between stationary pin and rotating disk was measured using load cell, while wear was measured using a Linear Voltage Differential Transformer (LVDT) sensor. The disk was designed to have a groove in order to ensure that the tested lubricants do not flow out during the rotation of disk. The disk was cleaned with acetone before each test. To ensure good repeatability of the results and a more precise evaluation of the tribological properties, each test was repeated twice under the same conditions.

\subsection{Materials}

The pin used in this research was made up of pure aluminum A1100, and the disk was made up of tool steel SKD11. The density of A1100 was $2.71 \mathrm{~g} / \mathrm{cm}^{3}$, and SKD11 was $7.85 \mathrm{~g} / \mathrm{cm}^{3}$. The dimensions of the pin were $6 \mathrm{~mm}$ in diameter and $30 \mathrm{~mm}$ in length, while the geometry of the disk was $160 \mathrm{~mm} \times 10 \mathrm{~mm}$. A schematic diagram of hemispherical pin and grooved disk is shown in Figure 2.

\subsection{Lubricants}

The refined, bleached and deodorized (RBD) palm kernel was used in this study, with and without ZDDP additive. Concentrations added into the RBD palm kernel were $1 \%, 3 \%$, and $5 \%$ in weightage. Commercial mineral oil (SAE 40) was used as a benchmark.

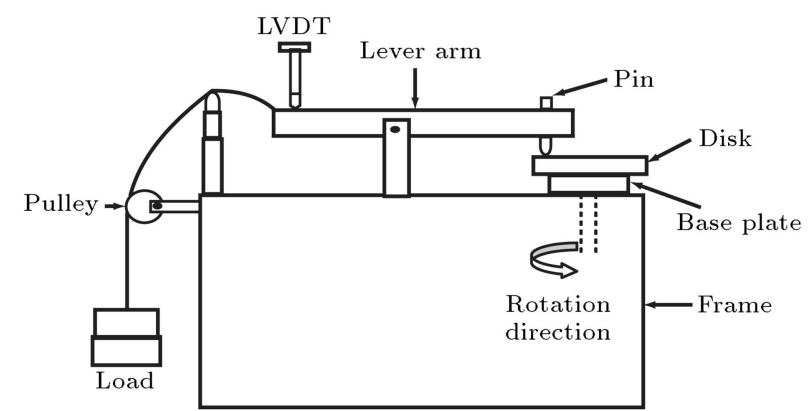

Figure 1. Schematic diagram of pin-on-disk tribotester.

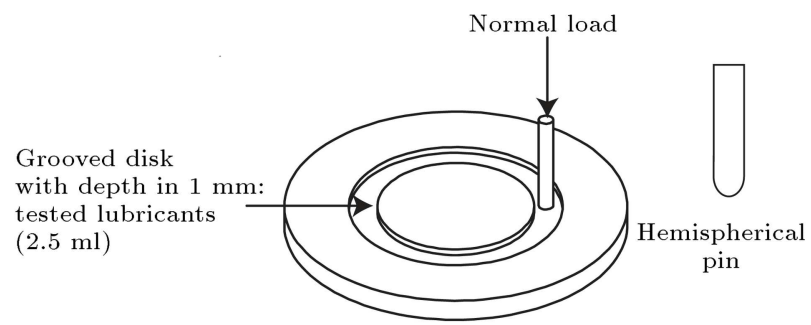

Figure 2. Schematic diagram of hemispherical pin and grooved disk. 
Table 1. Physical properties of SAE 40 and RBD palm kernel.

\begin{tabular}{lccc}
\hline \multicolumn{1}{c}{ Lubricant } & SAE 40 & RBD Palm Kernel & Test method \\
\hline Specific density at $25^{\circ} \mathrm{C}\left(\mathrm{g} / \mathrm{cm}^{3}\right)$ & 0.86 & 0.89 & ASTM D1298-85 (90) \\
Dynamic viscosity at $40^{\circ} \mathrm{C}(\mathrm{mPa} \mathrm{s})$ & 114.0 & 29.4 & ASTM D2983 \\
Dynamic viscosity at $100^{\circ} \mathrm{C}(\mathrm{mPa} \mathrm{s})$ & 17.8 & 10.0 & ASTM D2983 \\
Viscosity Index (VI) & 181.0 & 354.5 & ASTM D2270 \\
\hline
\end{tabular}

The contact point of the pin and rotating disk was lubricated with only a limited amount of lubricant $(2.5 \mathrm{ml})$. Table 1 shows the comparison of some general properties of RBD palm kernel and mineral oil (SAE 40). A mixture of RBD palm kernel and ZDDP additive was prepared in volumes of $100 \mathrm{~g}$. The two substances were mixed using a mixer at a high speed for about 1 hour and heat at $40^{\circ} \mathrm{C}-50^{\circ} \mathrm{C}$ in order to gain a homogeneous mixture.

\section{Experimental procedure}

The friction reduction property and anti-wear property of ZDDP in RBD palm kernel were evaluated using a pin-on-disk tribotester. The stationary pin was in contact with the disk at a constant vertical force, while the disk was rotated at a specified speed, creating a sliding contact. All tests were carried out with a sliding speed of $2.5 \mathrm{~m} / \mathrm{s}$ for 60 minutes under $9.8 \mathrm{~N}$ load with a mean contact Hertz pressure of $0.62 \mathrm{GPa}$ at $25^{\circ} \mathrm{C}$ temperature $\left( \pm 2^{\circ} \mathrm{C}\right)$. The pins were cleaned with acetone before and after each test. The mass loss of the pin will be measured by electronic balance for wear rate calculation.

\subsection{Friction analysis}

The resistance to the motion (frictional force) was measured using a load cell connected to the pin, and the values were taken directly from the software with an installed image acquisition system. The coefficient of friction was calculated by dividing the normal force which is pressing the pin against the disk, as shown in Eq. (1) [18]:

$$
\mu=F_{f} / F_{n},
$$

where $F_{f}$ is frictional force due to two contacting bodies in motion (in unit $\mathrm{N}$ ), and $F_{n}$ is normal force pressing the same two bodies together (in unit $\mathrm{N}$ ).

\subsection{Surface analysis}

\subsubsection{Wear measurements}

The effectiveness of ZDDP additive in wear reduction was identified by measuring the wear scar diameter on the pins. The wear scar diameter on the pins was measured by an optical microscope to calculate the wear volume (V) as in Eq. (2) [19]. The mass loss of the pin was measured before and after the test with an electronic balance (minimum $0.1 \mathrm{mg}$ ). The pin volume loss was obtained to calculate the wear rate using Eq. (3) [10]:

$$
V=\pi r^{4} / 4 R,
$$

where $r$ is radius of pin wear scar (in unit $\mathrm{mm}$ ), and $R$ is original pin radius (in unit $\mathrm{mm}$ ):

$$
Q=\Delta V / s,
$$

where $Q$ is wear rate (in unit $\mathrm{mm}^{3} / \mathrm{m}$ ), $\Delta V$ is volume loss (in unit $\mathrm{mm}^{3}$ ), and $s$ is sliding distance (in unit $\mathrm{m})$.

\subsubsection{Worn surface}

The worn surface of the pins was analyzed after each test and was measured using an optical microscope. The surface analysis of the worn pins was important to prove that ZDDP additive can improve the anti-wear performance of the RBD palm kernel. To ensure that there is no excess oil on the pin's surface, the pins were cleaned carefully after each test.

\subsubsection{Surface finish measurement}

Surface roughness of the pins was measured at the end of the experiment by a surface profiler. Surface roughness parameter, $\mathrm{Ra}$, was used to describe the surface features of the wear components and, at the same time, to analyze the influence of the lubricants used. The initial pin surface roughness value was below Ra $0.02 \mu \mathrm{m}$.

\section{Results}

\subsection{Determination of lubrication regime}

In order to determine the lubrication regime of the operating lubrication system, the minimum film thickness was calculated using elastohydrodynamic film thickness calculations, and the equation was given in Eq. (4) [20]. All information with respect to geometry and calculated lubricant constants is given in Table 2:

$$
\begin{aligned}
H_{\min }= & 3.63 U^{0.68} G^{0.49} W^{-0.073}\left(1-e^{-0.68 k}\right) \\
H_{\min }= & 3.63\left(\frac{\eta_{0} V}{E^{\prime} R_{x}}\right)^{0.68}\left(\alpha E^{\prime}\right)^{0.49}\left(\frac{F}{E^{\prime} R_{x}^{2}}\right)^{-0.073} \\
& \left(1-e^{-0.68 k}\right) .
\end{aligned}
$$


Table 2. Geometry and calculated lubricant constants.

\begin{tabular}{lc} 
Curvature of the pin, $R_{x}$ & $0.003 \mathrm{~m}$ \\
Effective elastic moduli, $E^{\prime}$ & $6.169 \times 10^{10} \mathrm{~Pa}$ \\
Dynamic viscosity at $27^{\circ} \mathrm{C}, \eta_{0}:$ & \\
$\eta_{0 \text { (SAE40) }}$ & $0.198 \mathrm{~Pa} . \mathrm{s}$ \\
$\eta_{0 \text { (RBD palm kernel) }}$ & $0.0397 \mathrm{~Pa} . \mathrm{s}$ \\
Surface velocity of the disk, $V$ & $2.5 \mathrm{~m} / \mathrm{s}$ \\
Normal load, $F$ & $9.8 \mathrm{~N}$ \\
Pressure viscosity coefficient, $\alpha$ & $2.1 \times 10^{-8} \mathrm{~Pa}$ \\
Elliptical parameter, $k$ & 1.0339 \\
Dimensionless speed parameter, $U:$ & \\
$U_{(\text {SAE40) }}$ & $2.675 \times 10^{-9}$ \\
$U_{(\text {RBD palm kernel) }}$ & $5.363 \times 10^{-10}$ \\
Dimensionless material parameter, $G$ & 1279 \\
Dimensionless load parameter, $W$ & $1.77 \times 10^{-5}$ \\
\hline
\end{tabular}

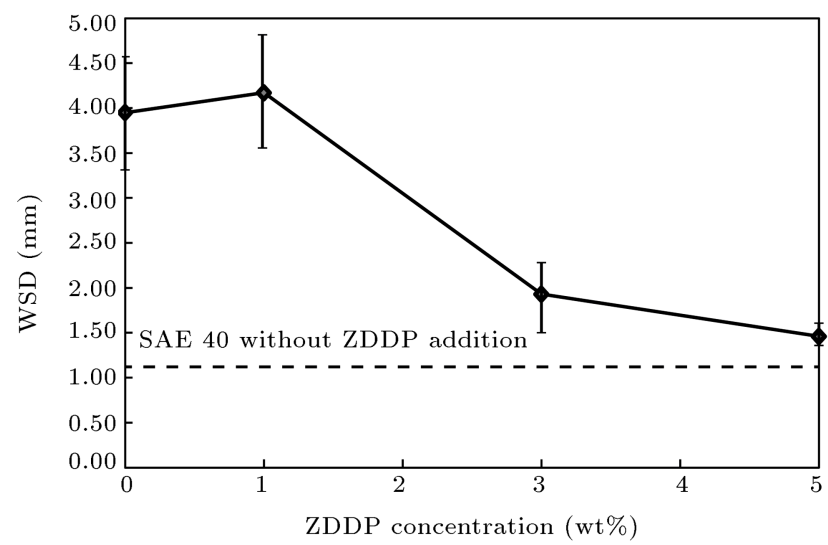

Figure 3. The effect of ZDDP additive concentration on wear scar diameter.

Then, the lubrication regime can be calculated by determining the dimensionless film parameter, also called lambda ratio, as seen in Eq. (6):

$$
\lambda=\frac{H_{\min } \cdot R_{x}}{\sqrt{R_{q 1}^{2}+R_{q 2}^{2}}},
$$

where $R_{q 1}$ and $R_{q 2}$ are the root mean square roughnesses of the two solid surfaces. In the present study, the values of rms roughness of pin and disk are $0.43 \mu \mathrm{m}$ and $0.35 \mu \mathrm{m}$, respectively. The calculated lambda ratios for SAE 40 and RBD palm kernel were 1.0869 and 0.3645 , respectively, which clearly indicate that this lubrication system operates in the boundary and mixed lubrication regime.

\subsection{Anti-wear performance}

Figure 3 indicates that with an increase in additive concentration, the Wear Scar Diameter (WSD) of RBD palm kernel increases slightly; when the concentration

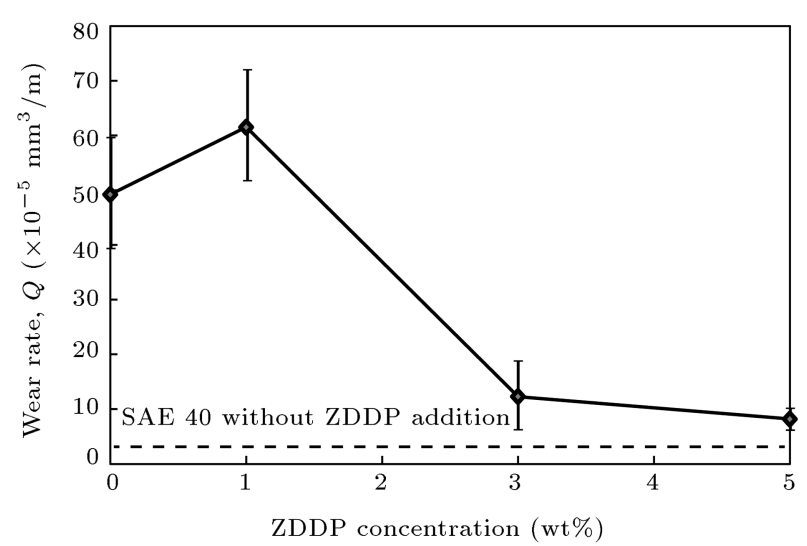

Figure 4. Wear rate at different ZDDP concentrations.

of ZDDP additive is lower than $1 \mathrm{wt} \%$, it then reduces rapidly. The smallest value of WSD was observed when 5 wt\% of ZDDP was added into RBD palm kernel, where a large reduction of about $63 \%$ occurred when 5 wt\% of ZDDP was added into RBD palm kernel compared with the oil without ZDDP. However, RBD palm kernel with $5 \mathrm{wt} \%$ ZDDP still has a lower antiwear performance compared with SAE 40. SAE 40 performed better with a lower $23 \%$ WSD than RBD palm kernel did, with 5 wt\% ZDDP.

The effectiveness of ZDDP additive in wear reduction was clearly identified by calculating both volume loss and wear rate of the pins. The volume of the pin wear was calculated as per Eq. (2) analytically after the measurement of wear scar diameter on the pin surfaces. Then, the wear rate was calculated as per Eq. (3) after measuring the mass loss of the pins with an electronic balance. The wear rate is defined as the volume loss per sliding distance. Figure 4 presents the plot data of wear rate. The results exhibit that the presence of ZDDP additive greatly affects the wear rate. These data also show a similar pattern with the WSD value, as in Figure 3, in which RBD palm kernel has the best anti-wear performance when ZDDP additive added is $5 \mathrm{wt} \%$. Reduction in wear rate with an increase in ZDDP concentration after 1 wt $\%$ concentration also proves that the ZDDP additive can effectively control wear in RBD palm kernel since ZDDP is able to protect a metal-to-metal contact.

\subsection{Friction-reducing performance}

The curves in Figure 5 show the distribution of Coefficient Of Friction (COF) for all tested lubricants against the sliding time. As shown in Figure 5, PK + 1\% ZDDP has high and unsteady coefficient of friction until 1800 s sliding time, and then, it comes down and becomes stable after $2400 \mathrm{~s}$. For PK + 3\% ZDDP, it has a progressively increasing peak of COF when the sliding time is below $600 \mathrm{~s}$. However, PK $+3 \%$ ZDDP has almost similar COF with SAE 40 after 1200 s sliding time and reaches a steady condition. The COF curves 


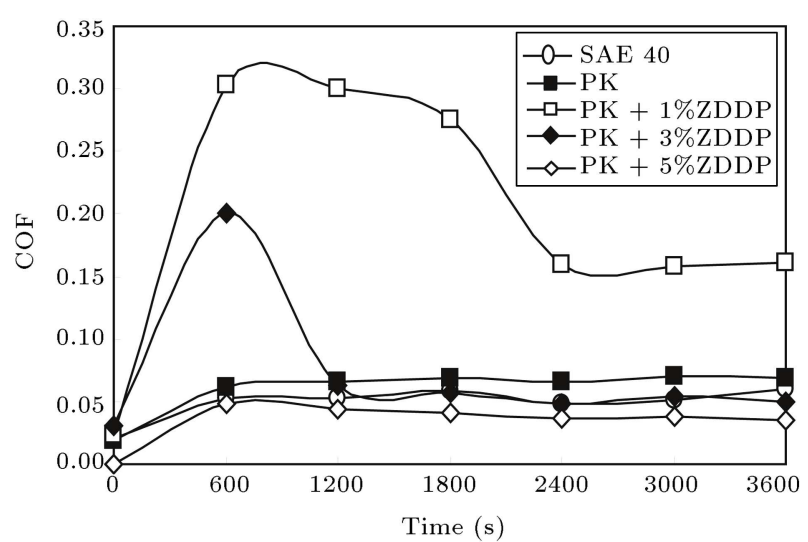

Figure 5. Coefficient of friction against sliding time.

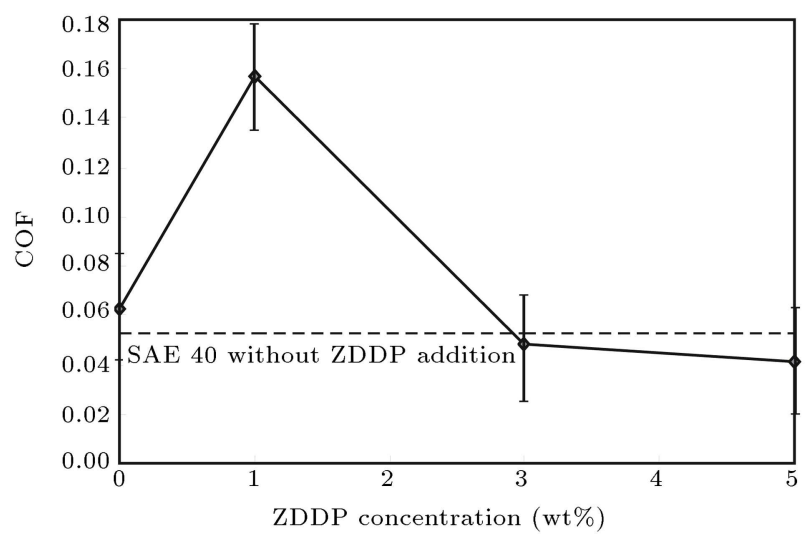

Figure 6. The effect of ZDDP additive concentration on coefficient of friction.

of SAE 40, PK and PK + 5\% ZDDP are smoother and steadier after $600 \mathrm{~s}$ sliding time. This indicates that the presence of ZDDP additive in RBD palm kernel will make this lubricant perform well as an anti-friction property at the certain concentration.

The friction properties of ZDDP additive in RBD palm kernel at $9.8 \mathrm{~N}$ load as the function of concentration are shown in Figure 6 . The results show that this additive greatly increases Coefficient Of Friction (COF) of RBD palm kernel when the additive concentration is less than $1 \mathrm{wt} \%$. However, COF reduced when the additive concentration increased above $1 \mathrm{wt} \%$. ZDDP additive shows better an anti-friction performance when the concentration is $5 \mathrm{wt} \%(0.041)$. The trends observed were consistent with the wear rate data, in which the presence of $5 \mathrm{wt} \%$ ZDDP in RBD palm kernel gave the lowest friction force, compared with other concentration and pure PK. Figure 6 also illustrates that RBD palm kernel $+5 \mathrm{wt} \%$ ZDDP has a better friction performance compared with SAE 40, where the difference is approximately at $21 \%$.

\subsection{Surface roughness analysis}

Surface roughness of the pin was measured using surface profiler after completion of each test. The

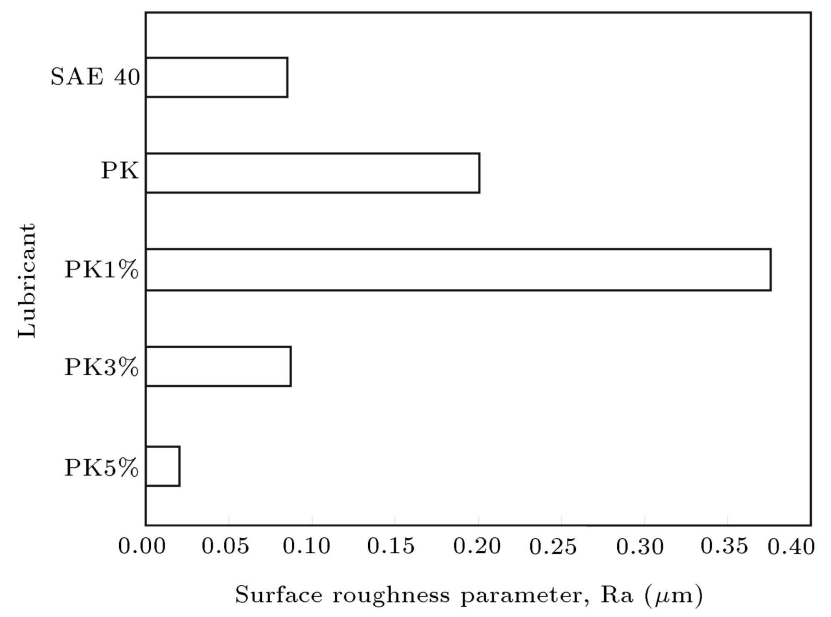

Figure 7. Surface roughness value on the pin surface after each test.

measurement was taken perpendicular to the direction of sliding. Figure 7 plots the pin roughness values, while Figure 8(a)-(e) show the surface topographies of the surface roughness on the pin surface. According to the results in Figure 7, surface roughness value, Ra, has a direct relationship with coefficient of friction. The pin runs in RBD palm kernel with 1 wt\% ZDDP concentration, which has the highest surface roughness. Surface roughness of the pin becomes smoother as the concentration of ZDDP increases, and the same applies to the trend in friction performance. This result indicates that $5 \mathrm{wt} \% \mathrm{ZDDP}$ additive in $\mathrm{RBD}$ palm kernel can also maintain the surface finish of the rubbing surfaces.

\subsection{Worn surface analysis}

The surface analysis of the pin was conducted using an optical microscope to deduce the effects of ZDDP concentration on the wear behavior. The pin surfaces were cleaned by acetone before taking the photomicrograph to ensure that there is no excess oil and debris deposited on the surfaces. The photomicrograph of the worn surface at low magnification $(20 \times)$ and their slider profile are shown in Table 3 . Figure 9 shows the photomicrograph of the worn surface using high resolution microscope with $200 \times$ magnification. From these results (Table 3 and Figure 9 ), it is clearly shown that severe abrasive wear has occurred on the worn surface of PK and PK $+1 \%$ ZDDP. The increase in ZDDP concentration showed an improvement on the worn surfaces where light groove is detectable on the worn surface of PK $+3 \%$ ZDDP. Further increase in ZDDP concentration gives minimum wear, where the worn surface of $\mathrm{PK}+5 \%$ ZDDP only shows slight frictional tracks. Worn surface of SAE 40 also shows slight frictional tracks. Smooth slider profiles of both SAE 40 and PK $+5 \%$ ZDDP point to the evidence that they have slight frictional tracks. 


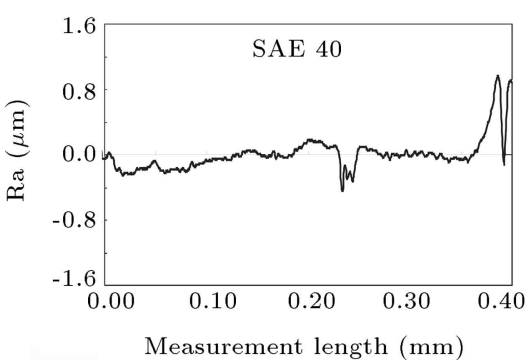

(a)

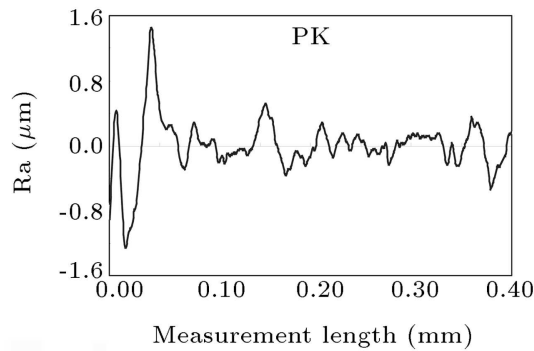

(b)

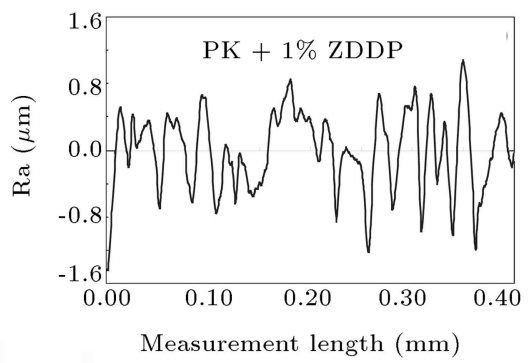

(c)

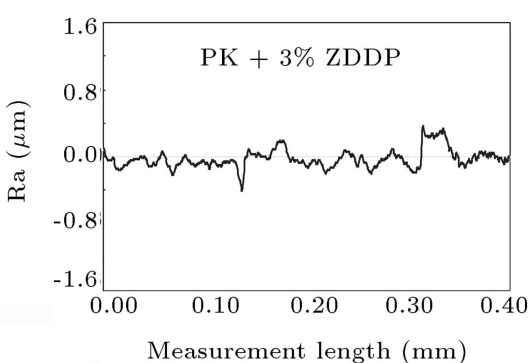

(d)

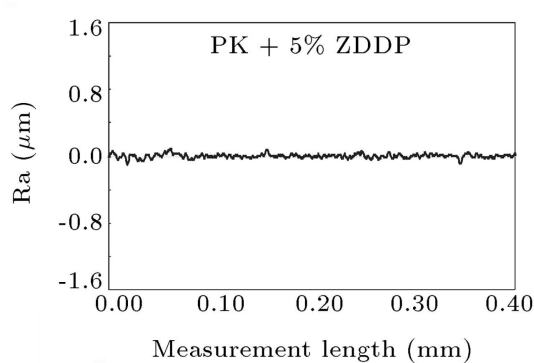

(e)

Figure 8. Surface topographies of pin surface: (a) SAE 40, (b) RBD palm kernel (PK), (c) PK + 1\% ZDDP, (d) PK + $3 \%$ ZDDP, and (e) PK + 5\% ZDDP.

Table 3. Photomicrograph and slider profile of the pin worn surfaces.

\begin{tabular}{|c|c|c|c|}
\hline Lubricant & WSD, $x(\mathrm{~mm})$ & Slider profile* & Photograph \\
\hline SAE 40 & 1.12 & & \\
\hline PK & 3.95 & & \\
\hline $\mathrm{PK}+1 \% \mathrm{ZDDP}$ & 4.17 & & \\
\hline $\mathrm{PK}+3 \% \mathrm{ZDDP}$ & 1.93 & & \\
\hline $\mathrm{PK}+5 \% \mathrm{ZDDP}$ & 1.46 & & \\
\hline
\end{tabular}

* Slider profile refer to profile view across the track;

$\mathrm{PK}=\mathrm{RBD}$ palm lernel;

ZDDP = Zinc dialkyldithiophosphate:

WSD $=$ Wear Scar Diameter. 


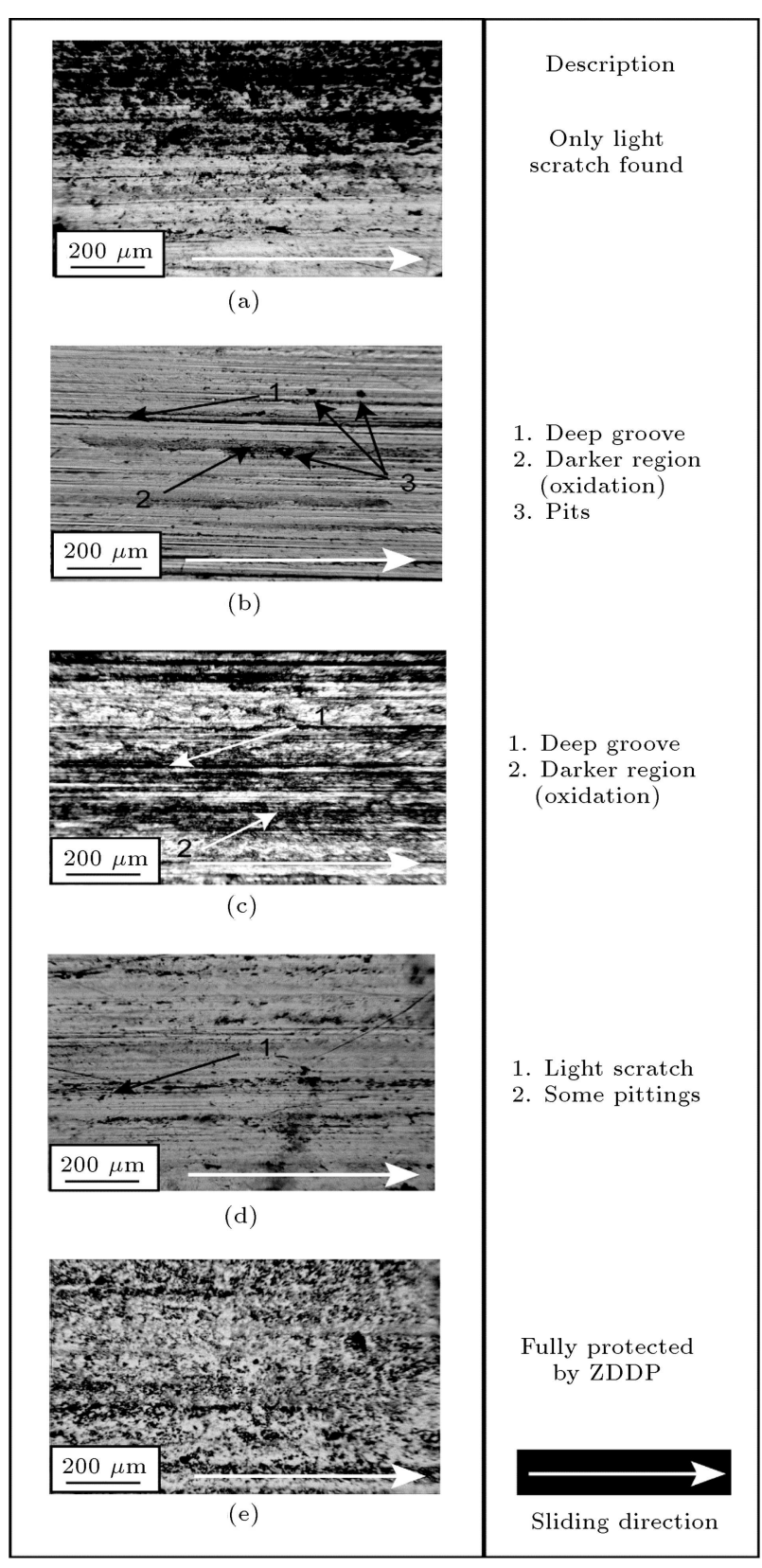

Figure 9. Wear worn surfaces of the pins: (a) SAE 40, (b) RBD palm kernel (PK), (c) PK + 1\% ZDDP, (d) PK $+3 \%$ ZDDP, and (e) PK $+5 \%$ ZDDP.

\section{Discussion}

Figure 3 suggests that ZDDP additive increases wear scar diameter when the concentration is below $1 \mathrm{wt} \%$. Castro et al. [21] stated that the effectiveness of the additives depends on the chemistry of the base oil and additives; the number of active sites on the surface will affect the rate of reactivity of the base oils and additives with the surface. It is possible that, at $1 \mathrm{wt} \%$ concentration, ZDDP only plays a secondary role in the formation of tribofilm which causes high wear scar diameter. However, further increase in concentration reduces wear scar diameter since ZDDP is able to form a low-shear strength surface film that can protect the surfaces from contact [22]. At high concentration, ZDDP additive can be adsorbed onto the metal surfaces effectively and form a thin film between the contact surfaces to protect the surfaces against wear [1].

From Figure 5, it can be seen that stable antifriction layers of SAE $40, \mathrm{PK}$, and PK $+5 \%$ ZDDP are developed on the surface after $600 \mathrm{~s}$. PK $+5 \%$ ZDDP has a stable coefficient of friction through the operation time after $600 \mathrm{~s}$ because ZDDP additive is able to be adsorbed on or react with the metal surfaces and function effectively to form a protective layer. The thick film was also formed on the surfaces when the additive reacts with oxide layer on the aluminum surface $[23,24]$. On the other hand, fatty acid contents in RBD palm kernel are able to form monolayers of metal soaps on the interface surfaces and create a stable film to reduce a metal-to-metal contact [5]. RBD palm kernel has probably high polarity where it is able to form a close-packed monolayer and a stable adsorbed film to prevent the metal-to-metal contact. This is in agreement with a statement made by Zhang et al. [25], stating that a polar lubricant would generally improve the stability of the surface-adsorbed film, thus minimizing coefficient of friction.

Figure 5 also shows that PK $+3 \%$ ZDDP peaks at $600 \mathrm{~s}$, and then coefficient of friction becomes stable after $1200 \mathrm{~s}$. This state is attributed with the slower rate formation of ZDDP tribofilm at which it is unable to prevent high friction. At such a state, shear stress of the tribofilm also might be high, hence contributing to high coefficient of friction. This is because ZDDP additive can function effectively as friction-reducing property depending on the shear strength of the protective film formed [16]. Besides, coefficient of friction of $\mathrm{PK}+1 \% \mathrm{ZDDP}$ is higher at the beginning until $1800 \mathrm{~s}$, because the asperities of the sliding surfaces are flattened at that time, but the values seem to drop and become stable after the equilibrium friction force conditions are realized. PK $+1 \%$ ZDDP has high coefficient of friction for a long period of time (until $1800 \mathrm{~s}$ ) because the competitive adsorption and reaction occurs between the additive and base oil [26]. This competitive adsorption makes ZDDP unable to physically be adsorbed onto the metal surfaces to provide a thin film on the interfaces' surfaces to reduce friction.

Figure 6 indicates that the additive will exert antagonistic effect on the anti-friction performance when the concentration of ZDDP is below $1 \mathrm{wt} \%$, making the coefficient of friction increase rapidly. This was attributed to the competitive adsorption between additive and the base oil on the surface since both additive and base oil have high polarity [26]. At this concentration, the shear strength of the adsorbed film is high where high shear strength will result in 
high coefficient of friction [25]. On the other hand, when the concentration of ZDDP further increases, the friction appears to reduce, since ZDDP is adsorbed onto the metal surfaces chemically, forming a protective and stable film that can reduce friction. This means that the formation of lubrication layers depends on the concentration of ZDDP additive on the metal surface.

Surface roughness of pin surface was analyzed to find the relationship between finished surfaces after each test with coefficient of friction. It was found that the coefficient of friction has a direct relationship with surface roughness. The pins that were run in PK + $1 \%$ ZDDP had the highest surface roughness, while pins in $\mathrm{PK}+5 \%$ ZDDP had the lowest. Figures 7 and 8 clearly show that lower $\mathrm{Ra}$ value has small variations in asperity height, indicating that it has less metal-to-metal contact. These results also exhibit that, after $1 \mathrm{wt} \%$ of ZDDP concentration, ZDDP additive functions effectively as an anti-wear agent to form a protective tribofilm which leads to lower shear strength between metallic friction pairs. The tribofilm will penetrate into the surface which makes the surface smoother and reduces coefficient of friction at the same time, thus preventing a direct metal-to-metal contact to improve the wear resistance of the metallic friction pairs [27].

The abrasive groove on the pin surface (Table 3 ) increases the surface roughness. From the observation, when the abrasive groove on worn surface of the pin is deeper, it will increase friction and surface roughness value. The small value of surface roughness indicates that the pin surface is smoothened, where the best lubricant will provide smoother surface. Further analysis on the worn surface is shown in Figure 9. It can be seen that there is a darker region on worn surface of PK and PK $+1 \%$ ZDDP. This darker area represents oxidation which occurs on that surface. Triglyceride structure in the vegetable oil is already known to have good lubricity; however, this structure brings the drawbacks to the vegetable oil. Poor oxidation stability is one of the main problems in vegetable oil that occurs due to the rapid reactions of unsaturated double bonds in the fatty acids and strong intermolecular reactions to form a lubricant film [28].

Oxidation will eventually weaken the metal surface and cause more material removal or wear debris [9]. These wear debris will cut directly into the soft surface (aluminum), hence creating deep groove (PK and PK $+1 \%$ ZDDP). Without ZDDP additive, RBD palm kernel will undergo oxidation since the presence of oxygen $\left(\mathrm{O}_{2}\right)$ will eventually affect the reactions within the lubricant [29]. Based on Figure 9, PK + 5\%ZDDP shows a smooth wear pattern compared to the other tested lubricants. At this concentration, ZDDP is believed to be competing for the available oxygen to reduce oxide formation. ZDDP is able to protect the metal surface from rapid oxidation and wear since ZDDP can form a low shear strength layer of iron compounds (iron sulphide and iron phosphide) [16]. In addition, ZDDP seems to be a good anti-wear agent due to phosphates content which is very reactive towards metal surface to form a polymer-like layer on the surface during friction [30]. Smooth surface on the worn area, no darker region, and reduction in wear scar diameter, collectively, prove that ZDDP plays an effective role as an anti-wear and anti-oxidant additive.

\section{Conclusion}

The effectiveness of ZDDP additive in RBD palm kernel was evaluated using the pin-on-disk tester in terms of tribological performance (anti-wear property and friction reducing property). The following conclusions are made based on the discussion above:

- The tribological tests showed that RBD palm kernel with 5 wt $\%$ ZDDP had better coefficient of friction (about 21\%) than SAE 40 did. However, the antiwear property is much lower (about 23\%);

- The results also indicate that both anti-wear and anti-friction properties of RBD palm kernel improved with ZDDP addition at concentration above $1 \mathrm{wt} \%$;

- 5 wt $\%$ ZDDP concentration showed the best tribological performance, compared to other concentrations. At this concentration, ZDDP is able to protect the surface against wear and oxidation. Therefore, the coefficient of friction, wear rate, and surface roughness values were reduced.

\section{Acknowledgement}

The authors would like to express their gratitude to the Faculty of Mechanical Engineering, Universiti Teknologi Malaysia (UTM) for their support and cooperation during this study. The authors also thank Research Management Centre (RMC), UTM for the Research University Grant (02G34, 02G35, 09H64) and Fundamental Research Grant Scheme (4F610) for their financial support.

\section{References}

1. Twist, C.P., Bassanetti, I., Snow, M., Delferro, M., Bazzi, H., Chung, Y.W., Marchio, L., Marks, T.J., and Wang, Q.J. "Silver-organic oil additive for hightemperature applications", Tribol. Lett., 52(2), pp. 261-269 (2013).

2. Emami, M., Sadeghi, M.H., Sarhan, A.A.D., and Hasani, F. "Investigating the minimum quantity lubrication in grinding of $\mathrm{Al}_{2} \mathrm{O}_{3}$ engineering ceramic", J. Clean. Prod., 66, pp. 632-643 (2014). 
3. Joseph, D.K. and Sharma, P.V. "Improvement of thermooxidative stability of non-edible vegetable oils of Indian origin for biodegradable lubricant application", Lubr. Sci., 22, pp. 149-161 (2010).

4. Siniawski, M., Saniei, N., Adhikari, B., and Doezema, L.A. "Influence of fatty acid composition on the tribological performance of two vegetable-based lubricants", J. Synth. Lub., 24, pp. 101-110 (March 2007).

5. Shahabuddin, M., Masjuki, H.H., Kalam, M.A., Bhuiya, M.M.K., and Mehat, H. "Comparative tribological investigation of bio-lubricant formulated from a non-edible oil source (Jatropha oil)", Ind. Crops. Prod., 47, pp. 323-330 (2013).

6. Quinchia, L.A., Delgado, M.A., Reddyhoff, T., Gallegos, C., and Spikes, H.A. "Tribological studies of potential vegetable oil-based lubricants containing environmentally friendly viscosity modifiers", Tribol. Int., 69, pp. 110-117 (2014).

7. Haseeb, A.S.M.A., Sia, S.Y., Fazal, M.A., and Masjuki, H.H. "Effect of temperature on tribological properties of palm biodiesel", Energy, 35, pp. 14601464 (2010).

8. Zulkifli, N.W.M., Kalam, M.A., Masjuki, H.H., Shahabuddin, M., and Yunus, R. "Wear prevention characteristics of a palm oil-based TMP (trimethylolpropane) ester as an engine lubricant", Energy, 54, pp. 167-173 (2013).

9. Ing, T.C., Mohammed Rafiq, A.K., Azli, Y., and Syahrullail, S. "The effect of temperature on the tribological behavior of RBD palm stearin", Tribol. Trans., 55(5), pp. 539-548 (2012).

10. Syahrullail, S., Izhan, M.I., and Mohammed Rafiq, A.K. "Tribological investigation of RBD palm olein in different sliding speeds using pin-on-disk tribotester", Sci. Iran. B, 21(1), pp. 162-171 (2014).

11. Lam, M.K., Tan, K.T., Lee, K.T., and Mohamed, A.R. "Malaysian palm oil: Surviving the food versus fuel dispute for a sustainable future", Renew. Sustain. Energy Rev., 13, pp. 1456-1464 (2009).

12. Ghosh, P. and Karmakar, G. "Evaluation of sunflower oil as a multifunctional lubricating oil additive", Int. J. Ind. Chem., 5(7), pp. 1-10 (2014).

13. Syahrullail, S., Azwadi, C.S.N., and Ing, T.C. "The metal flow evaluation of billet extruded with RBD palm stearin", Int. Rev. Mech. Eng., 5(1), pp. 21-27 (2011).

14. Somayaji, A. and Aswath, P.B. "Antiwear behavior of ZDDP and fluorinated ZDDP in the presence of alkylated diphenyl amine antioxidants", Tribol. Trans., 51(4), pp. 403-412 (2008).

15. Mahipal, D., Krishnanunni, P., Mohammed Rafeekh, P., and Jayadas, N.H. "Analysis of lubrication properties of zinc-dialkyl-dithio-phosphate (ZDDP) additive on Karanja oil (Pongamia pinnatta) as a green lubricant", Int. J. Eng. Res., 3(8), pp. 494-496 (2014).

16. Jayadas, N.H., Prabhakaran Nair, K., and Ajithkumar, G. "Tribological evaluation of coconut oil as an environment-friendly lubricant", Tribol. Int., 40(2), pp. 350-354 (2007).

17. Asadauskas, S.J., Biresaw, G., and Mcclure, T.G. "Effects of chlorinated paraffin and ZDDP concentrations on boundary lubrication properties of mineral and soybean oils", Tribol. Lett., 37(2), pp. 111-121 (2010).

18. Ibrahim, R.A. and Ali, W.Y. "Tribological performance of polyester composites filled by vegetable oils. [Tribologische eigenschaften von polyesterverbunden mit pflanzlichen Ölen], Materwiss, Werksttech, 41(5), pp. 287-292 (2010).

19. Ŏ̆uz, H., Düzcükoğlu, H., and Ekinci, Ş. "The investigation of lubrication properties performance of eurodiesel and biodiesel", Tribol. Trans., 54(3), pp. 449-456 (2011).

20. Zulkifli, N.W.M., Masjuki, H.H., Kalam, M.A., Yunus, R., and Azman, S.S.N. "Lubricity of bio-based lubricant derived from chemically modified jatropha methyl ester", Jurnal Tribologi, 1, pp. 18-39 (2014).

21. Castro, W., Weller, D.E., Cheenkachorn, K., and Perez, J.M. "The effect of chemical structure of basefluids on antiwear effectiveness of additives", Tribol. Int., 38(3), pp. 321-326 (2005).

22. Rohatgi, P.K., Tabandeh-Khorshid, M., Omrani, M., Lovell, M.R., and Menezes, P.L., Tribology for Scientists and Engineers (2013).

23. Glovnea, R.P., Olver, A.V., and Spikes, H.A. "Effectiveness of boundary lubricant additives on some coated surfaces", Life Cycle Tribol., 48, pp. 135-143 (2005).

24. Imran, A., Masjuki, H.H., Kalam, M.A., Varman, M., Hasmelidin, M., Al Mahmud, K.A.H., Shahir, S.A., and Habibullah, M. "Study of friction and wear characteristic of jatropha oil blended lube oil", Procedia. Eng., 68, pp. 178-185 (2013).

25. Zhang, W., Zeng, X., and Wu, H. "The tribological chemistry of a novel borate ester additive and its interaction with ZDDP using XANES and XPS", Tribol. Lett., 53(3), pp. 533-542 (2014).

26. Zhan, W., Song, Y., Ren, T., and Liu, W. "The tribological behaviour of some triazine - dithiocarbamate derivatives as additives in vegetable oil", Wear, 256(34), pp. 268-274 (2004).

27. Zhang, Z., Yamaguchi, E.S., Kasrai, M., and Bancroft, G.M. "Interaction of ZDDP with borated dispersant using XANES and XPS", Tribol. Trans., 47, pp. 527536 (2004).

28. Fox, N.J. and Stachowiak, G.W. "Vegetable oil-based lubricants-A review of oxidation", Tribol. Int., 40(7), pp. 1035-1046 (2007).

29. Ing, T.C., Rafiq, A.K.M., Azli, Y., and Syahrullail, S. "Tribological behaviour of refined bleached and 
deodorized palm olein in different loads using a fourball tribotester", Sci. Iran., 19(6), pp. 1487-1492 (2012).

30. Unnikrishnan, R., Jain, M.C., Harinarayan, A.K., and Mehta, A.K. "Additive-additive interaction: an XPS study of the effect of ZDDP on the AW/EP characteristics of molybdenum based additives", Wear, 252(3-4), pp. 240-249 (2002).

\section{Biographies}

Azman Nurul Farhanah completed her BS and MS degrees in Mechanical Engineering at Universiti
Teknologi Malaysia, Malaysia in 2014 and 2016, respectively. She is currently pursuing her $\mathrm{PhD}$ degree in Mechanical Engineering, and her research is related to the development of biolubricant.

Samion Syahrullail obtained his PhD degree in Engineering from Kagoshima University, Japan in 2007. His major field of study is tribology in metal forming. He is currently a Senior Lecturer at the Department of Thermofluid, Faculty of Mechanical Engineering, Universiti Teknologi Malaysia. His research interests include development of biolubricant, palm oil research, and fluid mechanics. 